\title{
Spatial protected area decisions to reduce carbon emissions from forest extraction
}

Article

Accepted Version

Albers, H. J., White, B., Robinson, E. J. Z. and Sterner, E. (2020) Spatial protected area decisions to reduce carbon emissions from forest extraction. Spatial Economic Analysis, 15 (3). pp. 280-298. ISSN 1742-1780 doi:

https://doi.org/10.1080/17421772.2019.1692143 Available at https://centaur.reading.ac.uk/87774/

It is advisable to refer to the publisher's version if you intend to cite from the work. See Guidance on citing.

To link to this article DOI: http://dx.doi.org/10.1080/17421772.2019.1692143

Publisher: Taylor \& Francis

All outputs in CentAUR are protected by Intellectual Property Rights law, including copyright law. Copyright and IPR is retained by the creators or other copyright holders. Terms and conditions for use of this material are defined in the End User Agreement.

\section{www.reading.ac.uk/centaur}

\section{CentAUR}

Central Archive at the University of Reading 
Reading's research outputs online 


\section{Spatial Protected Area Decisions to Reduce Carbon Emissions from Forest Extraction}

HJ Albers, Department of Economics - 3985, College of Business, University of Wyoming, Laramie, Wyoming 82071; jo.albers@uwyo.edu

B White, Department of Economics - 3985, College of Business, University of Wyoming, Laramie Wyoming 82071; bwhite27@uwyo.edu

EJZ Robinson, School of Agriculture, Policy, and Development, University of Reading, Reading, UK; e.j.robinson@reading.ac.uk

E Sterner, Environment for Development, School of Business, Economics and Law, University of Gothenburg, Gothenburg, Sweden; erik.sterner.work@gmail.com

Abstract. Protected Areas (PA) can mitigate climate change by reducing carbon emissions that result from forest loss. Carbon emissions from forest degradation are a large component of forest loss and are often driven by the extraction decisions of resource-dependent households. PA policies must reflect how villagers use forests to be effective. Here, a spatial Nash equilibrium of extractors' uncoordinated forest extraction pattern decisions establishes a baseline of forest use patterns. Using that baseline, a manager chooses the location and enforcement level of PAs to maximize the avoided forest degradation in the landscape and in the PAs. Optimal PA locations depend on the labor market and the distance between forest patches. A combination of wageimproving projects and appropriately located protected areas increases avoided forest degradation.

JEL codes: Q2, Q23, Q56, C63, C31

Keywords: spatial Nash equilibrium, REDD, forest degradation, carbon sequestration, deforestation, leakage, systematic conservation planning, spatial optimization, enforcement, spatial prioritization 


\section{Introduction}

Protected Area (PA) policies, sometimes implemented as Reducing Emissions from Forest Degradation and Deforestation (REDD) Protected Forests, can mitigate climate change by reducing carbon emissions that result from forest loss. Although often ignored in the policy literature and in practice, particularly in many African countries, carbon emissions from forest degradation are a large component of forest loss (Pearson et al., 2017; Murdiyarso et al., 2008; Asner et al., 2005). With rural, resource-dependent villagers undertaking forest extraction that drives forest degradation, efficient implementation of PA policies should reflect villagers' extraction decisions and their potential reactions to policies aimed at generating avoided carbon emissions.

While PAs may be established and managed for a wide range of conservation benefits, some PAs are created to address climate change by avoiding forest degradation's carbon releases, such as PAs formed through REDD. Although broader REDD programs may implement REDD as a payment for ecosystem services, PES, with payments made conditional on the amount of avoided forest loss, such programs prove difficult in settings where forest property rights are poorly defined and enforced, and with community and individual forest extraction in de facto open access forests (Sommerville et al., 2010). In response to these and other challenges with REDD implemented as a PES, many countries and communities establish REDD protected areas (REDD PAs) and enforce extraction restrictions within those REDD PAs (Brandon \& Wells, 2009). As with many PAs in low/middle income countries (LMICs), the cost of optimal levels of enforcement can exceed enforcement budgets, even when those budgets are supported by REDD general funds at the country level (Börner et al., 2014). 
Understanding how villagers change their forest extraction choices (quantities and locations) in response to PAs enables managers to make more effective use of a limited budget. During our fieldwork, villagers described their forest extraction decisions - particularly where and how much they extract - as a function of distance costs, other uses of time, the actions of other villagers, and the policy setting (e.g. Albers \& Robinson, 2007). Although resources may be fully or partially protected within the PA, if people continue to extract in the PA or displace their resource extraction to other less-protected forests, the PA's net impact on avoided forest degradation is reduced. If the PA is part of a REDD strategy, given that a unit of carbon emitted is equally costly to climate change wherever it is produced, climate change mitigation is also reduced (Robinson et al., 2011). Because siting PAs is an inherently spatial problem and the reaction of villager extraction to PAs also occurs across space, achieving positive outcomes at the landscape level from REDD PA policy requires anticipating and accounting for the changes in resource users' extraction behavior as a spatial reaction to the policy.

Here, we use the model of the uncoordinated villager spatial forest extraction decisions of in a spatial Nash equilibrium from Sterner, et al. (2018) to reflect these characteristics of villager extraction decisions. The solution method here differs from Sterner et al., holding similarities with other models such as Bayer and Timmins (2005) and Timmins and Murdock's (2007) spatial Nash bargaining game. The model accommodates a reasonably realistic extraction setting in which not all villagers extract in the same areas of the forest or cooperate to approach a social planner's solution. Villagers consider the management scheme in place - the location and enforcement level of PAs in the forest landscape. We embed the villager extraction model and spatial Nash equilibrium in a manager's optimization decision to choose PA locations and enforcement levels to produce avoided carbon emission benefits by reducing forest degradation 
from villager extraction. We analyze the outcomes from this model for two labor market settings and two forest distance settings, and consider PA policies coupled with projects that increase wages that provide conservation benefits by creating a more valuable use of non-extraction labor.

\section{The Model}

The model considers two types of actors on the landscape who can affect the stock of a resource, a landscape manager and individual villagers who harvest the resource which is sold or valued at a particular price. The manager can influence where and for how long individuals' extract by choosing where to locate "no take" protected areas and the extent to which the protected area extraction restriction is enforced. This enforcement is reflected in a cost imposed on those villagers who choose to extract illegally from the PA at the risk of being caught. The manager has full information about the individuals including their response to the implementation of the PA scheme. Similarly, individual villagers know the location of the PAs and the probability of being caught, and that the other villagers will also be making spatially explicit extraction choices. Each period, each individual chooses how to allocate their time to extracting across a spatial landscape and to wage labor in their village. After a period of extraction, the resource then regrows via an exogenous density dependent growth process. The outputs of the model presented are in the steady state when harvest equals growth and consist of the stock of the resource in each patch and each individual villager's income. The model of villagers and their interactions here is identical to the model explored in Sterner et al. (2018) and the development of the model below draws from that paper.

\subsection{The Spatial Setting}

The spatial setting for this model has a village with $N$ individuals who can act as extractors or work in the village for wage labor, or a combination, situated a distance $d_{i}$ from the 
beginning of a patchy resource landscape. The landscape (Figure 1) has three patches arranged in a two by three grid, with three patches per ray located at increasing distance from the village. Between-ray distance is denoted as $d_{r}$ and $d_{i}$ is the distance between patches in the same ray. The patch locations are indexed by $\{r, p\}$ where $r \in\{1,2\}$ is the ray and $p \in\{1,2,3\}$ is the patch. We assume that travel cannot occur diagonally between rays. The cost in terms of an individual's time spent travelling to a set of patches, $l_{i, d}$, varies depending on which of the patches are visited.

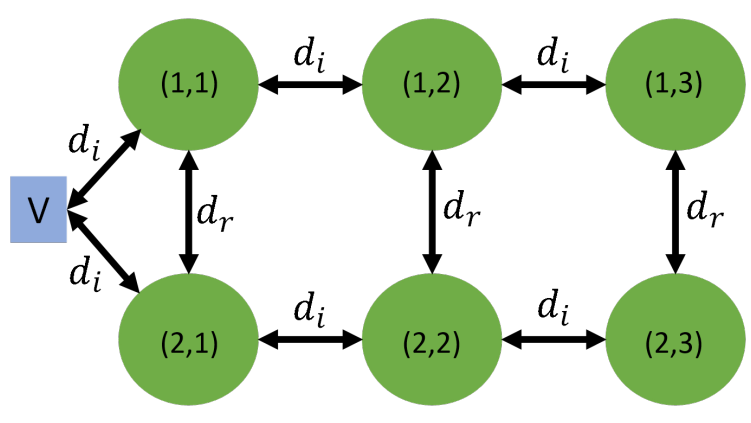

Figure 1: Spatial landscape showing village, resource patches, distance between patches

\subsection{The Extractor's Problem}

Equilibrium locations and time allocations of extraction for each individual are determined in the model from a Nash Equilibrium of a group of ex ante identical extractors who can make heterogeneous choices. The extractors allocate time among forest extraction labor, a non-resource wage labor option, and fixed costs of travel to access forest patches. An equilibrium is reached when the summation over individuals' choices results in a steady state total harvest per patch, which is a function of total labor time per patch, $H_{r, p}=H\left(L_{r, p}\right)$.

Each individual villager $i$ maximizes their individual expected net income $E \pi_{i}$ by choosing how to allocate their total labor, $L$, across resource extraction in each $\{r, p\}$ patch, $l_{i, r, p}$, and wage labor, $l_{i, w}$, given the stock of resource in each patch, $X_{r, p}$, time in distance, $l_{i d}$, 
and the extraction coefficient or "catchability" $q$. The amount of the resource extracted by the individual, $\sum_{r, p} h_{i, r, p}\left(l_{i, r, p}\right)$, is sold at an exogenous price $m$ (or valued at that price). There are diminishing returns to total labor extraction time, reflected in the parameter $\gamma$ in the modified Schaefer harvest function. Wage labor income sees diminishing returns to total wage labor time via the parameter $\beta$ in a similar fashion to the total harvest in each patch.

The individuals know the probability of getting caught harvesting illegally in each patch that is a protected area, $e_{r, p}$. The assumed consequences of being caught extracting illegally are that the harvest from this patch is lost to the individual and is then sold by the village at price $m$. Each extractor then chooses their labor allocations given what the other extractors are doing by solving:

$$
\max _{l_{i, r, p}, l_{i, w}}\left[E \pi_{i}\right]=\left[m \sum_{r, p} h_{i, r, p}\left(l_{i, r, p}\right)+\omega_{i}\left(l_{i, w}\right)\right]
$$

subject to

Individual labor constraint: $L_{i}=\left(\sum_{r, p} l_{i, r, p}\right)+l_{i, w}+l_{i, d}$

Total harvest over all extractors: $H_{r, p}=q X_{r, p}\left(L_{r, p}\right)^{\gamma} ; \gamma<1$

Proportion of total harvest to extractor $i: h_{i, r, p}=\frac{l_{i, r, p}}{L_{r, p}}\left(1-e_{r, p}\right) H_{r, p}$ Individual wage labor income: $\omega_{i}\left(l_{i, w}\right)=w \cdot \frac{l_{i, w}}{L_{w}} \cdot\left(L_{w}\right)^{\beta} ; \beta<1$

Because the extractors consider every other extractor's decision, the solution to the model is a spatial Nash equilibrium. Between periods, the resource in each patch partially regenerates after it has been harvested, $\Delta R_{r, y}$, according to a logistic growth function:

$$
\Delta X_{r, p}=g \cdot\left(X_{r, p}-H_{r, p}\right) \cdot\left(1-\frac{X_{r, p}-H_{r, p}}{K_{r, p}}\right)
$$




$$
X_{r, p}^{\prime}=X_{r, p}-H_{r, p}+\Delta X_{r, p}
$$

In the preceding equations, $g$ is the natural growth rate, $K_{r, p}$ is the patch carrying capacity and $X_{r, p}^{\prime}$ is the resource stock after the regrowth. This paper considers the long run socio-ecological steady state (after sufficient time periods such that $X_{r, p}^{\prime} \approx X_{r, p}$ ) and the corresponding spatial Nash equilibrium of extraction decisions.

\subsection{The Manager's Problem}

The manager maximizes the steady state level of avoided degradation in the landscape $(A D L S)$ by choosing the location of PAs throughout the landscape and the level of enforcement in each PA. The manager faces a budget constraint $(B)$, which is the maximum amount that the manager can spend on enforcement to achieve the goal, and a constraint on the total amount of the landscape available for PAs. ${ }^{1}$ In the absence of enforcement, the steady state value of the resource in each patch is $X_{r, p}^{0}$. With enforcement, the steady state value of avoided degradation in each patch is $A D_{r, p}=X_{r, p}-X_{r, p}^{0}$. For expositional convenience, it is assumed that the enforcement cost function is a linear function of the enforcement probabilities in each patch such that $c\left(e_{r, p}, d_{i}, d_{r}\right)=c_{e} e_{r, p}$. The ADLS manager, therefore, chooses the enforcement probabilities across the landscape to maximize the steady state avoided degradation, subject to a budget constraint and a constraint on the number of PAs in the landscape:

$$
\max _{e_{r, p}} A D=\sum_{r, p}\left(X_{r, p}-X_{r, p}^{0}\right)
$$

subject to

\footnotetext{
${ }^{1}$ The appendix considers a case in which the enforcement cost function contains both the variable cost of enforcement within a patch and a distance cost of reaching the patch.
} 


$$
\begin{gathered}
\sum_{r, p} c_{e} e_{r, p}=B \\
\text { if } e_{r, p}>0 \text { then } P A_{r, p}=1 \\
\sum_{r, p}\left(P A_{r, p}\right) \leq 3
\end{gathered}
$$

In addition, another manager maximizes the avoided degradation within PA sites; this ADPA manager solves:

$$
\max _{e_{r, p}} A D=\sum_{r, p}\left(P A_{r, p}\right)\left(X_{r, p}-X_{r, p}^{0}\right)
$$

subject to the same constraints.

\subsection{Solution Method}

The discreteness of the distance costs between pairs of forest patch implies a nonconvexity in the individual's optimization problem, making the model analytically intractable at both the individual and aggregate level. The intractability necessitates the need for numerical methods to solve this problem. With similarities to Sterner, et al. (2018), the solution method uses iterated best response to find the long run non-cooperative Nash equilibrium of labor allocation and extraction location decisions in pure strategies. Within the spatial landscape, ten basic villager strategy types, in terms of location and number of patches from which to extract, emerge. These strategy types range from specializing in wage labor, to specializing in extraction from one patch, to extraction from various subsets or all patches. Because travel times are discrete, continuous optimization methods cannot be implemented. However, within each strategy type, the decisions, objective functions, and constraints are all continuous and an 
individual determines the optimal labor allocation for each strategy type and then chooses the best strategy type to undertake.

Using iterated best response does not guarantee that a Nash equilibrium in pure strategies will be found. It does, however, help to know that at least one Nash equilibrium in pure strategies exists. Using discrete fixed-point theorems, Sato and Kawasaki (2009) show that a condition that guarantees that a Nash equilibrium in pure strategies exists is the ability to order the best responses of each person as a function of everyone else's strategies in such a way as to be monotonic. Given that there is only one unique solution to each person's optimization problem, we are guaranteed to be able to order the responses to all possible combinations of strategies such that this condition is met.

We assume period-by-period (myopic) optimization by the extractors. The noncooperative solution method searches iteratively for spatial patterns of individual labor allocations that maximize each individual extractor's income, given the actions of all other individuals. After each period, the forest regenerates. We repeat this process until resource stocks and labor allocations show a stable repeating pattern that forms a steady state, which we use for analysis here (see Sterner et al. 2018 for further description of a similar solution method to the same model without the manager).

2.5 Motivating parameter choices for distance and enforcement costs

The on-going costs of enforcing access restrictions are largely ignored in the REDD and PA siting literatures and in management decisions (Robinson et al., 2019; Albers et al. 2017; Rakatama et al., 2016). Börner et al. (2014) and Brimont et al. (2017) find enforcement costs of $15 \%-20 \%$ of opportunity or compensation costs for Brazil's REDD programs and for a REDD+ pilot project in Madagascar, respectively. The widespread "paper park" phenomenon points to 
the lack of enforcement in many PAs and that many PAs do not enforce at high enough rates to protect resources (e.g. Bruner et al., 2004; Albers et al., 2017). Considering these ranges, we employ enforcement budgets at three levels (low, medium, high) that constrain both the manager's choices of the number and enforcement level of the PAs. The low budget limits the maximum enforcement level to $50 \%$ in a one-patch PA or $1 / 6^{\text {th }}$ of the landscape and limits the maximum enforcement level to $8.7 \%$ if enforcement is spread evenly across 6 PA patches; the medium budget permits $100 \%$ enforcement in a one-patch PA; and the high budget allows $100 \%$ and $50 \%$ enforcement in two PAs, $25 \%$ enforcement in 6 PA patches, and combinations in between. With international agreements encouraging countries to conserve $20-30 \%$ of land area and with current low levels of enforcement budgets, these budget cases reflect a realistic range of the parameters in which PA siting and enforcement decisions in low-income countries are made. The value of non-timber forest products (NTFPs) and fuelwood to rural households varies widely but many studies emphasize their importance to cash income and to "effective" income, including Cavendish (2000)'s estimate of poor Zimbabwe households relying on such extraction for $40 \%$ of their income (Robinson et al., 2010; Cavendish, 2000). In addition, the time households, particularly women, commit to both traveling to/through forests and to forest extraction activities also varies widely but can be a significant fraction of their labor time or caloric intake, and depends on the accessibility of the forest in terms of travel time (Macdonald et al., 2001; Edmunds, 2002; Pattanayak et al. 2004), We choose parameters to calibrate the model to generate spatial patterns, levels, and time commitments of resource extraction and PA fractions of the landscape and enforcement levels that reflect diverse but realistic low-income country PA budgets and rural resource dependence observed in the field and in the literature.

\section{The Benchmark Cases}


For the managers to discern the avoided forest degradation from their PA decisions, they must know the pre-policy, or base case, pattern of extraction. Here, we establish the base case spatial extraction for 4 landscape settings in a $2 \mathrm{X} 2$ design to compare settings with and without a functioning labor market and with a low or a high distance cost.

\subsection{No Wage Setting}

In the no-wage setting, with a low distance cost to the closest patch of $5 \%$ of total individual labor time available, every individual extracts in 2 neighboring patches (Table 1). For example, 4 villagers extract from the two patches closest to the village, $(1,1)$ and $(2,1)$, in different rays. In contrast, 4 other sets of 4 villagers each extract from 2 neighboring patches on either ray 1 or ray 2 before returning to the village along the same ray. These sets of villagers extract less from their more village-proximate patch of their two patches than their most distant patch - for example, spending less labor time in $(1,2)$ than in $(1,3)$ - due to the presence of other extractors in those sites, which decreases the value of individual labor in extraction. The 2 sets of 4 villagers that extract in the most distant patches have the least labor time for extraction due to the high distance costs. Despite having less time for extraction, extractors in distant patches face the least competition for resources and consequently the smallest common pool resource externality and steady state stock effect. That dynamic aspect of the framework combines with the distance costs to generate higher levels of steady state extraction in more distant sites but also to higher levels of resource stocks in those sites in the steady state. In contrast to this 2-patch harvest per individual, in a high distance cost setting of $10 \%$ of total individual labor time to reach the nearest patch, each extractor visits only one patch (Table 1). The high distance cost leaves less time for extraction and villagers spread out and location-specialize to limit competition within patches and travel costs. In comparison to the low distance cost setting, the 
high distance cost creates higher steady state resource stocks everywhere, due to the reduction in labor time available for extraction, and to a pattern of resource with larger increases in steady state stock levels with distance from the village. Larger total income/harvest arises because the increased distance costs lead to larger equilibrium stock levels, which increases the marginal/average return to extraction labor everywhere.

In these no-wage base case settings, the comparison of extraction patterns over distance demonstrates the role of distance fixed costs in generating the pattern of resource use and stocks in equilibrium. Higher distance costs limit extraction, which works against the common pool resource externality and steady state stock effect, thereby generating both higher steady state resource stocks and higher incomes from extraction. The impact of distance costs on reducing open access over-extraction also leads to higher net incomes in the high distance cost setting (7.93) than the low distance cost setting (3.65). The distance costs also generate larger differences in steady state stock sizes between near and distant patches. In both distance settings, with no opportunity to allocate labor to wage work, only the binding labor constraint limits extraction across the landscape.

Table 1: No wage setting. The no wage setting benchmark values for individuals' extraction labor time (as a fraction of their labor endowment) in all patches, and wage work, distance cost, and income when distance cost to the first patch, and between rays of patches, is $5 \%$ (low distance) and 10\% (high distance) of total individual labor time. The stock of the resource and harvest in each patch are shown in terms of percent carrying capacity.

\begin{tabular}{|c|c|c|c|c|c|c|}
\hline \multicolumn{7}{|c|}{ Low Distance } \\
\hline \multirow[b]{2}{*}{ \# Villagers } & \multicolumn{5}{|c|}{ Labor time allocations by patch, wage labor and travel } & \multirow[t]{2}{*}{ Indiv. Income } \\
\hline & Patch 1 & Patch 2 & Patch 3 & Wage & $\mathrm{d}$ cost & \\
\hline 4 & $0.43(\mathrm{~S})$ & & & & 0.15 & 0.18 \\
\hline $4(4 S)$ & 0.22 & 0.58 & & & 0.20 & 0.18 \\
\hline $4(4 S)$ & & 0.07 & 0.63 & & 0.30 & 0.18 \\
\hline
\end{tabular}




\begin{tabular}{|c|c|c|c|c|c|c|}
\hline $\begin{array}{l}\text { Total Labor } \\
\text { Time }\end{array}$ & 2.59 & 2.57 & 2.53 & 0.00 & 4.60 & \\
\hline $\begin{array}{c}\text { Resource Stock } \\
(\% \mathrm{~K})\end{array}$ & $19 \%$ & $20 \%$ & $23 \%$ & & & Total Income \\
\hline $\begin{array}{c}\text { Total Harvest } \\
(\% \mathrm{~K})\end{array}$ & $9.73 \%$ & $10 \%$ & $11.7 \%$ & & & 3.66 \\
\hline \multicolumn{7}{|c|}{ High Distance } \\
\hline & \multicolumn{5}{|c|}{ Labor time allocations by patch, wage labor and travel } & Indiv. Income \\
\hline \# Villagers & $(1,1)$ & $(1,2)$ & $(1,3)$ & Wage & $d$ cost & \\
\hline $3(3 \mathrm{~S})$ & 0.80 & & & & 0.20 & 0.39 \\
\hline $3(3 \mathrm{~S})$ & & 0.60 & & & 0.40 & 0.42 \\
\hline $4(4 S)$ & & & 0.40 & & 0.60 & 0.38 \\
\hline $\begin{array}{l}\text { Total Labor } \\
\text { Time }\end{array}$ & 2.40 & 1.80 & 1.60 & 0.00 & 8.40 & \\
\hline $\begin{array}{c}\text { Resource Stock } \\
(\% \mathrm{~K})\end{array}$ & $28 \%$ & $39 \%$ & $54 \%$ & & & Total Income \\
\hline $\begin{array}{c}\text { Total Harvest } \\
(\% \mathrm{~K})\end{array}$ & $14 \%$ & $17 \%$ & $22 \%$ & & & 7.93 \\
\hline
\end{tabular}

\subsection{With wage setting ${ }^{2}$}

A functioning labor market provides a wage work alternative to extraction. In such a setting, villagers allocate labor to forest extraction, distance to patches, and to wage work. Unlike

${ }^{2}$ The wage and no-wage cases here are not directly comparable because they use different catchability coefficients in order to elucidate differences in decisions and patterns of extraction. 
frameworks with constant returns, this framework includes income from forest extraction that reflects diminishing marginal returns to total labor in a patch and effective wage declines with the total labor in wage work. For the high and low distance cost settings, some villagers choose to specialize in wage work and do not extract from the forest, others allocate labor to both activities, and others specialize in forest extraction.

As in the no-wage setting, the individual decisions and patterns of resource extraction and stock reflect the impact of distance costs. For the low distance cost setting, each villager who extracts does so from 2 adjacent patches (in one ray or in both rays' closest patch) while 10 villagers specialize in wage work (Table 2). Again, resource stocks and harvest levels increase with distance from the village. As compared to the no-wage case, the wage opportunity reduces the amount of extraction labor in each location, which partly mitigates the open access overextraction issue and leads to higher resource stocks and harvest levels in the steady state. In the high distance cost setting, 12 extractors each specialize in harvesting from only one patch while 8 villagers specialize in wage work (Sterner et al., 2018). Fewer villagers focus on wage work in the high distance cost setting due to the higher income from extraction when distance costs limit the stock effect of open access extraction in the steady state. The high distance cost setting's forest stock levels increase with distance more steeply than in the low-cost setting. As compared to the high distance cost and no-wage setting in which distance costs mitigate open access overextraction, the even lower levels of labor for resource extraction in each location lead to higher resource stocks in each patch in the steady state, and to higher harvests except in the most distant patches.

Table 2: Wage Setting. The functioning labor market benchmark values for individuals' extraction labor time (as a fraction of labor endowment) in all patches and wage, distance cost, and income when distance cost to the first patch is 5\% (low distance) and 10\% (high distance) of 
total individual labor time. The total for each patch and wage are listed below. The stock of the resource and harvest in each patch are shown in terms of percent carrying capacity.

\begin{tabular}{|c|c|c|c|c|c|c|}
\hline \multicolumn{7}{|c|}{ Low Distance } \\
\hline & \multicolumn{5}{|c|}{ Labor time allocations by patch, wage labor and travel } & \multirow[t]{2}{*}{ Indiv. Income } \\
\hline \# Villagers & Patch 1 & Patch 2 & Patch 3 & Wage & $\mathrm{d}$ cost & \\
\hline 2 & $0.425(\mathrm{~S})$ & & & & 0.15 & 0.51 \\
\hline $2(2 S)$ & 0.28 & 0.52 & & & 0.20 & 0.51 \\
\hline $2(2 S)$ & & 0.15 & 0.55 & & 0.30 & 0.56 \\
\hline 10 & & & & 1.00 & 0.00 & 0.50 \\
\hline $\begin{array}{c}\text { Total Labor } \\
\text { Time }\end{array}$ & 1.40 & 1.35 & 1.10 & 10.00 & 2.30 & \\
\hline $\begin{array}{l}\text { Resource Stock } \\
(\% \mathrm{~K})\end{array}$ & $29 \%$ & $32 \%$ & $38 \%$ & $\begin{array}{l}\text { Wage } \\
\text { Income }\end{array}$ & $\begin{array}{l}\text { Extr. } \\
\text { Income }\end{array}$ & Total Income \\
\hline $\begin{array}{c}\text { Total Harvest } \\
(\% \mathrm{~K})\end{array}$ & $13.7 \%$ & $14.9 \%$ & $15.9 \%$ & $48 \%$ & $52 \%$ & 10.34 \\
\hline \multicolumn{7}{|c|}{ High Distance } \\
\hline & \multicolumn{5}{|c|}{ Labor time allocations by patch, wage labor and travel } & Indiv. Income \\
\hline \# Villagers & $(1,1)$ & $(1,2)$ & $(1,3)$ & Wage & $d \operatorname{cost}$ & \\
\hline $2(2 S)$ & 0.65 & & & 0.15 & 0.2 & 0.53 \\
\hline $2(2 S)$ & & 0.60 & & & 0.4 & 0.56 \\
\hline $2(2 S)$ & & & 0.40 & & 0.6 & 0.63 \\
\hline 8 & & & & 1.00 & 0 & 0.52 \\
\hline
\end{tabular}




\begin{tabular}{|c|c|c|c|c|c|c|c|c|}
\hline $\begin{array}{c}\text { Total Labor } \\
\text { Time }\end{array}$ & 1.31 & 1.20 & 0.80 & 8.58 & 4.80 & \\
\hline $\begin{array}{c}\text { Resource Stock } \\
(\% \mathrm{~K})\end{array}$ & $33 \%$ & $42 \%$ & $60 \%$ & $\begin{array}{c}\text { Wage } \\
\text { Income }\end{array}$ & $\begin{array}{c}\text { Extr. } \\
\text { Income }\end{array}$ & Total Income \\
\hline $\begin{array}{c}\text { Total Harvest } \\
(\% \mathrm{~K})\end{array}$ & $15.1 \%$ & $18.4 \%$ & $21.5 \%$ & $42 \%$ & $58 \%$ & 11.02 \\
\hline
\end{tabular}

\section{Policy Results: PAs, Enforcement, and Alternative Income Generating Projects}

The ADLS manager maximizes steady state avoided degradation over the entire landscape (ADLS), relative to the no-policy baseline patterns of resource extraction. The ADPA manager maximizes steady state avoided degradation within the PAs only (ADPA), relative to the baseline, without considering the effects of spatial leakage to other forest patches that occurs when labor moves from a PA patch to a non-protected patch - in determining the PAs. Here, each manager type selects up to 3 PA patches and their budget-constrained optimal enforcement level to alter villager extraction to produce ADLS and ADPA.

\subsection{Constrained Optimal PAs in the No Wage Settings}

\subsubsection{Low Distance Cost Setting}

The ADLS and ADPA managers choose the same locations and enforcement levels for all 3 budget levels (Figure 2 row 1). At the low budget, the managers use two PAs in the first and second patches closest to the village along one ray and enforce the more distant patch at a high level and the near-village patch at a low level. The moderate enforcement level in $(1,2)$ deters some extraction labor in that patch (Figure 2 row 3 ) and produces avoided forest degradation and carbon releases from that patch (Figure 2 row 2). The low enforcement level in $(1,1)$ does not reduce extraction as compared to no-enforcement the base case and permits 
negative avoided degradation in that patch (Figure 2, row 3). Despite the ongoing labor for extraction in that patch, the PA in that patch deters leakage of labor from the neighboring PA patch in $(1,2)$ that occurs without enforcement of a PA in $(1,1)$. In this no-wage setting, extraction labor "leaks" to all locations in the landscape, creating carbon releases and lower stocks than in the base case in all patches except the PA in $(1,2)$. At the moderate budget, both managers create a fully enforced PA in $(1,2)$, which creates complete deterrence of extraction and high levels of avoided degradation in that location (Figure 2 row 2, 3). The avoided degradation is partially offset by leakage of extraction labor across all other patches in the landscape. This PA enforcement pattern reflects that deterring extraction requires lower enforcement at a distance when distance is a cost to extractors (e.g. Albers, 2010). The same amount of spending on enforcement in the more village-proximate patches does not deter as much extraction nor create as much avoided degradation. At the high budget, the managers revert to having a PA in both $(1,1)$ and $(1,2)$, but they fully enforce in the closest patch to the village $(1,1)$ to create avoided degradation, and partially enforce in $(1,2)$ (Figure 2 row 1$)$. That pattern of enforcement generates complete deterrence of extraction and high avoided degradation in $(1,1)$ and nearly reduces leakage to the PA in site $(1,2)$, while generating leakage and negative avoided degradation across the rest of the forest patches. Across budgets, villagers spread their leakage of extraction labor across patches to create the spatial Nash equilibrium with zero spatial arbitrage opportunities (see negative AD in row 2 of Figure 2). Less well-enforced "secondary" PAs (such as $(1,1)$ at a low budget and $(1,2)$ for a high budget) reduce but do not eliminate leakage to those PA sites generated by the strong enforcement in the "primary" PAs, which more strongly drive the spatial patterns of extraction. Still, placing the "secondary PAs" next to the more heavily enforced "primary PAs" proves optimal due to the distance and route relationships 
in villager decisions. The resulting forest patterns reflect the PA locations. No difference between ADLS and ADPA manager choices arise because the leakage spreads evenly across patches in spatial arbitrage, which implies that the same configuration of PAs creates both the maximum ADLS and ADPA.

\subsubsection{Large Distance Setting}

In the no wage, high distance setting, the managers place enforced PAs close to the village across all budgets (Figure 2) and induce leakage of labor primarily to more distant patches in the PAs' ray. At the moderate budget, the managers achieve complete deterrence in that near-village PA and use a small amount of enforcement in the other ray's most distant patch to create a "secondary PA." The secondary PA deters some, but not all, leakage of labor to that patch, and large labor leakage occurs in the more distant patches of the primary PA's ray (Figure 2 row 6). At the high budget, managers place PAs in both ray's nearest-village patches but use a moderate level of enforcement in both PAs that does not deter all extraction in the PA, in contrast to their use of a very different enforcement levels and PA locations at the moderate budget. 

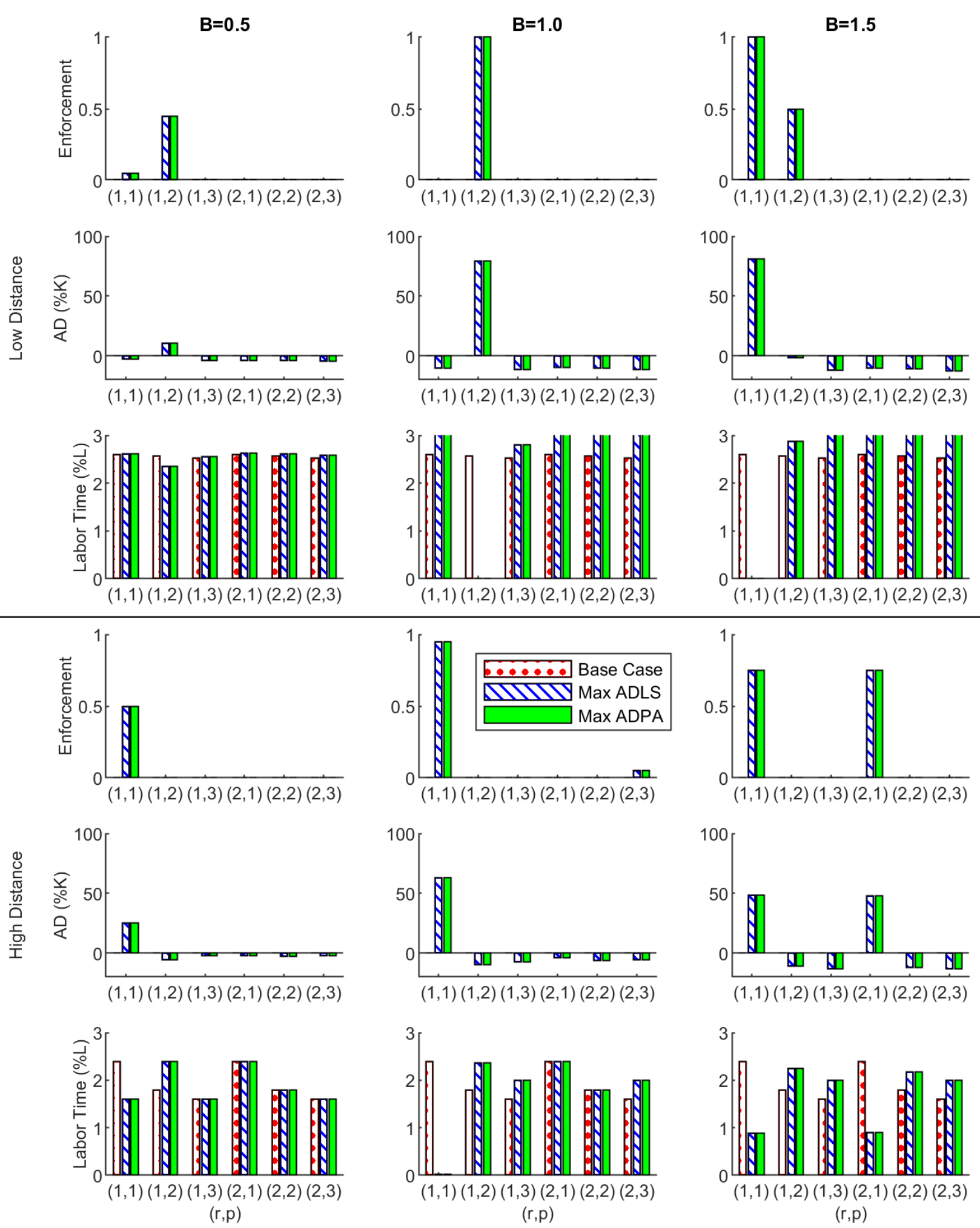

Figure 2:No wage setting. The optimal enforcement distribution when there is no functioning labor market and the distance cost to get to the first patch is 5\% (low distance) and 10\% (high distance). The resulting avoided degradation and labor time distributions are also shown. 


\subsection{Three Comparisons of Low and High Distance Settings in No Wage Setting.}

As above and as compared to the low distance cost setting, high distance costs create a strong spatial trend of lower labor allocations and harvests, and higher resource stocks, with distance from the village prior to the implementation of the PAs, in addition to higher stocks overall. This cost-based difference in extraction behavior influences the specific location of PAs and the level of enforcement. Because higher levels of enforcement are required to deter extraction in settings or in patches with low distance costs, managers in the low distance cost setting cannot induce much deterrence in the near-village patches until high budgets, and therefore always place a PA in an intermediate distance patch where enforcement and distance costs combine to create deterrence. In contrast, the managers in the high distance cost setting site PAs in the near-village patches where enforcement combines with distance costs to deter extraction from the PA. In addition, distance costs limit leakage of labor from the near-village PAs to more distant patches in the high distance cost setting.

\subsection{Functioning Labor Market Settings}

\subsubsection{Low Distance Setting}

The labor market setting (Figure 4) reflects relationships between distance cost and PAenforcement decisions similar to the no-wage or no-functioning labor market setting in terms of patterns. When managers have a At low budget, they place the PA far from the village, thereby using a combination of distance and a low probability of being caught to create avoided degradation. At an intermediate budget, managers locate a one-patch, well-protected PA near the village, while at still higher budgets, managers choose to enforce both a near-village PA and a distant PA in the opposite ray. 
Because villagers have the option to work for wage rather than extract, their response to enforced PA sites includes both increased labor in wage work and spatial leakage of labor for extraction to other patches, with the resulting level of leakage caused by the PA lower than in the no-wage setting with no labor allocated to a non-forest extraction use. Still, the PAs generate some spatial leakage of extraction labor to the most distant patches where, before policy intervention, relatively low levels of harvest occurs (Table 2). In contrast, locations next to PAs achieve avoided degradation - or reverse leakage (Figure 4, row 2). At low distances without PAs, villagers optimally harvest in 2 adjacent patches, but the PA site changes the income to previously profitable "routes" that now contain PAs, making that route less attractive and establishing avoided degradation in both PA and non-PA sites. These patterns of spatial leakage lead to different optimal patches for, and enforcement of, PAs for the ADLS versus the ADPA manager at a moderate budget. At that budget, the managers both enforce to near-deterrence in a near-village patch. The ADLS manager lightly enforces 2 "secondary" PAs outside of the primary PA's ray, which limits leakage and creates AD in both secondary PA patches and in an additional non-PA site, $(2,2)$ (Figure 4 row 2). The ADPA manager focuses on enforcing only one secondary PA in the opposite rays' near village patch to create AD there, and does not consider the leakage and degradation caused in the non-PA patches of the secondary PA's ray, particularly patch $(2,3)$ (Figure 4 row 2). At the high budget, however, the ADPA and ADLS managers enforce the same PAs, although not at identical levels due to the ADLS's consideration of leakage, particularly to site $(2,2)$ next to the PA site $(2,1)$.

The total village level income decreases as the PA budget increases. First, higher budgets permit more PAs or more enforcement, which drives labor out of the forest (Figure 3). As more labor leaves forest extraction and enters the labor market, wages decline. The decline in wages 
and the increased reliance on wage labor leads to lower incomes. Second, because less forest extraction labor leads to higher resource stocks through the stock effect, higher PA budgets decrease the labor in forest extraction but can increase the forest extraction income, which partially offsets the lost wage income.

\subsubsection{Large Distance}

At the low budget, both managers emphasize enforcement of a mid-distant patch $(1,2)$ for a "primary PA" with a moderate level of enforcement, where, prior to PA policy, 2 villagers harvested without allocating labor to wage work. In addition, the managers place a secondary PA, with a small amount of enforcement, to deter extraction in the opposite ray's nearest-village patch. Although this primary PA creates leakage to a distant patch $(1,3)$ beyond the PA, avoided degradation is created in both near village patches, $(1,1)$ and $(2,1)$. At the high budget, both managers enforce at high levels in the 2 patches closest to the village in a single ray, $(1,1)$ and $(1,2)$. That pattern creates little leakage and 2 PA patches with avoided degradation. At a moderate budget, however, ADLS and ADPA manager decisions diverge, although both have a primary PA close to the village in $(1,1)$. The ADLS manager imposes more enforcement on 2 secondary PAs and less on the primary PA than the ADPA manager, and the ADLS manager sites secondary PAs in the two most distant patches $(1,3)$ and $(2,3)$ while the ADPA manager sites secondary PAs in the near and far patches of the other ray, $(2,1)$ and $(2,3)$. The ADPA manager's patch and enforcement choices lead to non-PA patches with leakage that causes negative avoided degradation (Figure 4 row 5).

At the low budget, the implementation of PAs increases extraction income by solving some of the over-extraction problem from open access, both by replacing extraction labor with wage labor and by inducing extraction labor to leak to other patches. This increased extraction 
income, due to the PA's impact on labor and the stock effect, increases total income by offsetting the lower wage income. Moderate and high budget levels, however, allow enough enforcement to go beyond solving the open access over-extraction issue and to reduce total income as labor moves out of forest extraction to wage labor, causing wages to decline (Figure 3).
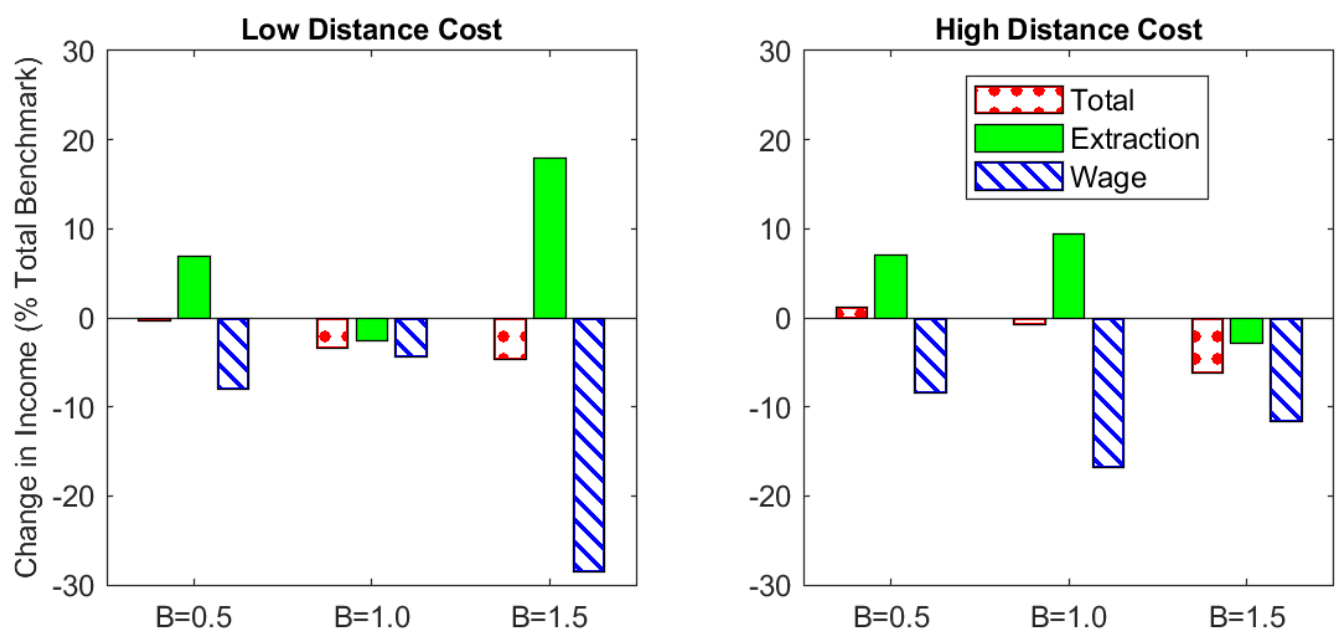

Figure 3: Labor market setting. The percent change in income relative to the total income in the benchmark case for total income, income from extraction, and wage income when there is a functioning labor market.

\subsubsection{Comparisons of Low and High Distance Settings in Functioning Labor Market Setting.}

The addition of an alternative to forest extraction for an income-generating use of labor leads to less forest extraction overall and to less leakage response to PAs than the no-wage setting. As in the no-wage setting, within a labor market setting, the PA patch locations and level of enforcement reflect distance costs and the extent to which PAs deter extraction based on those distance costs. Managers in the low distance cost setting choose PA patches at a higher distance from the village than managers in the high distance cost setting. In the moderate budget case, however, for both cost settings the managers site primary PAs near the village. In the high distance cost setting, managers enforce the primary PA at a lower level than in the low cost setting, and allocate more enforcement to secondary PAs located in both most distant patches where they create avoided degradation. 

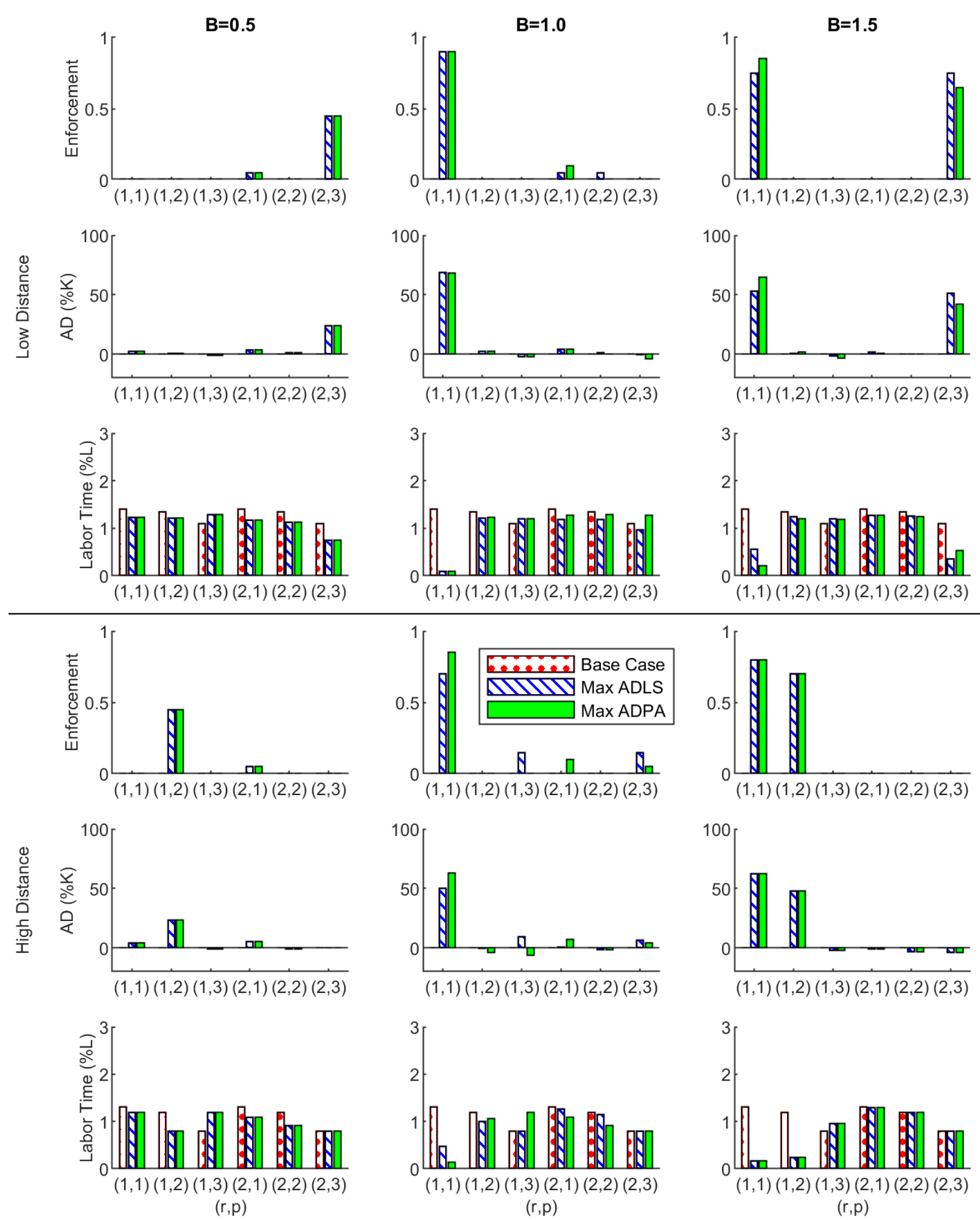

Figure 4: Labor market setting. The optimal enforcement distributions when there is a functioning labor market and the cost to get to the first patch is 5\% (low distance) and 10\% (high distance) of total labor time. The resulting avoided degradation (AD) and labor time distributions are also shown. 


\subsection{Combining PAs with projects that increase the wage}

As shown in several cases here, PAs can impose burdens on local resource-dependent people. Many countries routinely make "payments" to people living near PAs to compensate them for lost resource access. Such payment programs include cash payments to villages and projects such as building dispensaries or paying teacher's salaries. Unless those program benefits are explicitly conditional on avoided forest degradation, they act as compensation rather than as incentives for forest conservation, and can lead to increased demand for forest products through an income effect. Many "integrated conservation-development projects" (ICDPs), which often resemble REDD initiatives implemented as protected areas (Blom et al., 2010; Robinson et al., 2019), fail to create incentives for conservation because of a lack of conditionality or other mechanism to "integrate" villager decisions (Muller and Albers, 2004; Kerr and Jindal, 2007; Blom et al., 2010; Sunderlin and Sills, 2012; Bausch et al, 2014).

In a different type of approach aimed at increasing alternative livelihood options, some projects can generate higher wages in the village. Even without conditionality, higher wages can induce conservation outcomes when villagers respond to these higher wages by decreasing their time spent extracting in the forest, which can reduce both forest extraction and carbon releases. In our stylized model, we examine the impact of a wage-increasing project on avoided degradation through this mechanism of labor allocation with a fixed labor endowment, and compare that project alone to combining that project with PAs, both sequentially and simultaneously. We choose the functional labor market setting with a high distance cost (10\% to get to the first patch) to explore these projects and PA policy combinations.

First, we mimic a project that increases village wage by increasing the level of the exogenous wage paid to wage work from the base case to create a "wage only" project. That 
project increases total incomes to villagers, as compared to the base case without the project or PAs (Figure 5). In addition to making people better off by paying them more for their wage labor, the project induces villagers to increase their labor allocations to wage work and to decrease time spent extracting. The wage-raising project therefore creates a conservation mechanism by improving the income from non-forest related labor activities (Figure 5). ${ }^{3}$ Not surprisingly, villagers have higher incomes across all budgets with the wage-raising project, compared to when the managers only implement a PA policy and compared to the no project or PA situation. A PA-only policy increases overall incomes slightly for low budgets, but reduces incomes at moderate and high budgets (Figure 5). In addition, for the values used here, the PAonly policy generates less avoided degradation than the wage enhancing project in the low budget setting. Our third comparison involves starting with the (budget-constrained) optimal PAs from the no-project setting and adding the wage-improving project in sequence, which increases villager incomes less than the wage project alone, but generates more avoided degradation than the PA or wage project alone. Last, the simultaneous decision and implementation of the wage project with (budget-constrained) optimal PAs based on the postwage project extraction patterns generates higher incomes to villagers than the other PAinclusive policies at all budgets and the highest level of avoided degradation at all budgets (Figure 5). Although the relative costs of inducing avoided degradation through PA enforcement versus through wage-improving projects will vary case by case, this analysis demonstrates that combining the project and PAs can allow the wage-increasing project to provide compensating

\footnotetext{
${ }^{3}$ As in ongoing research, a fuller model could relate income to demand for forest resources; broaden the set of labor-using activities; and examine market access costs and constraints across labor, resource, and credit markets to more explore the impact of market function on PA policy (Muller and Albers, 2004).
} 
income to villagers while also inducing villagers to change their labor allocations, which generates conservation benefits and augments the effectiveness of PA enforcement expenditures. Here, the fixed labor and labor allocation decisions create a mechanism that integrates conservation and development actions.
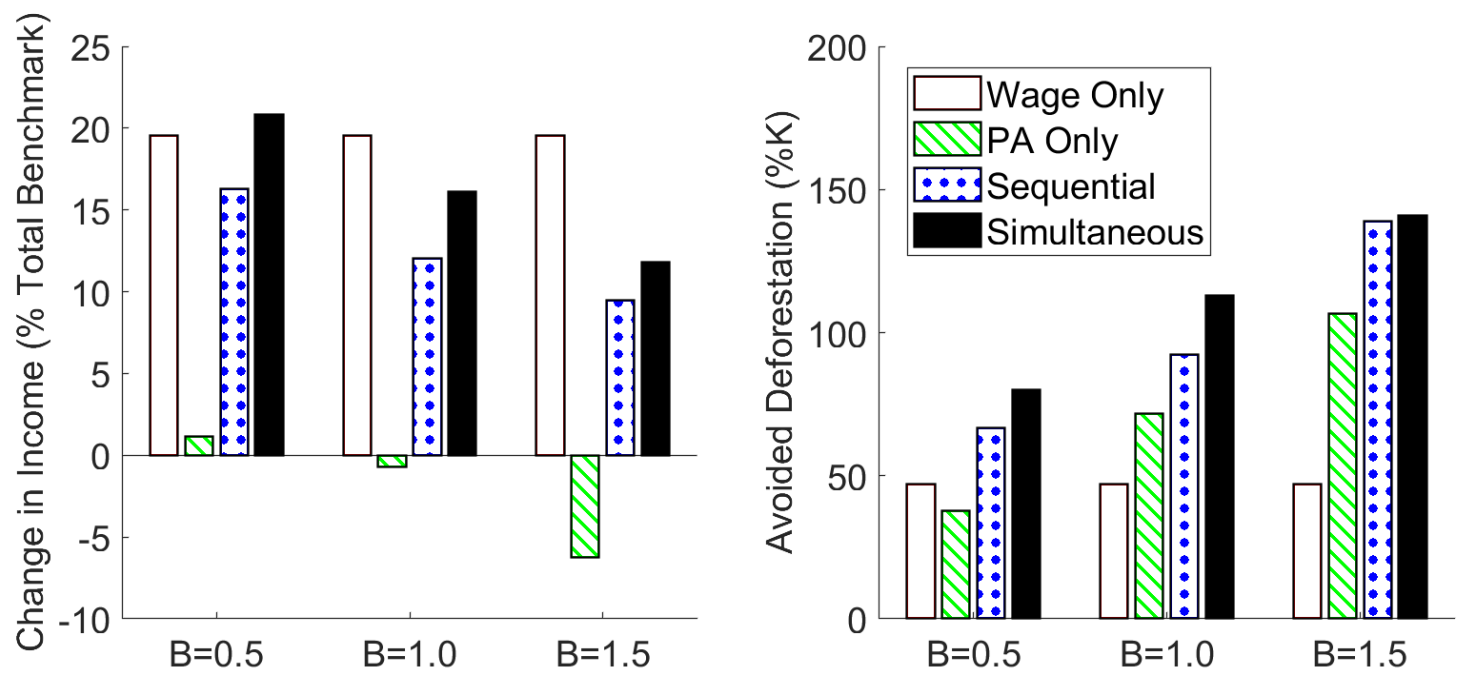

Figure 5: Comparison of total income and total avoided degradation to the village across four settings: 1.) Wage-increasing project only - the wage is increased but no PAs are introduce, 2.) PA only - Optimal PAs are introduced without changing the wage 3.) Sequential - The optimal $P A$ s are introduced without considering changing the wage and then the wage project is introduced, and 4.) Simultaneous - Optimal PAs determined while considering the wageincreasing project's impact

\section{Discussion}

These results have implications for the optimal locations of incompletely enforced REDD PAs within a landscape; for exploring the locations and levels of leakage in response to REDD PAs to generate avoided forest degradation and carbon releases; and for policies that address the burdens on local people from policies aimed at providing the global public good of climate control.

5.1. Optimal REDD PA locations and enforcement. 
How much additional carbon storage, or avoided carbon releases from forest degradation, a PA network creates depends on how that network alters the spatial decisions of the forest extractors that cause that degradation. Managers who understand how villagers consider distance costs when choosing where and how intensively to extract can strategically locate and enforce PAs that maximize avoided forest degradation by changing extraction behavior. The enforcement budget influences whether the manager locates a PA closer to the village or further away because the time cost of distance for extractors influences the level of enforcement necessary to change their extraction decisions. For example, in our model, managers with low budgets optimally site PAs far from the village in low distance cost settings, but closer to the village when extractors' distance costs are high. This finding resonates with the idea that distance alone can protect some forest patches from degradation caused by resource extraction (e.g. Albers, 2010). In addition, our findings suggest that managers concentrate enforcement spending in one PA to achieve large levels of deterred extraction rather than spreading enforcement out across many PAs due to the large carbon releases caused by the first units of forest extraction labor in a patch and the small carbon releases associated with adding more forest extraction labor to non-protected patches.

\subsection{Leakage and a landscape perspective}

Depending on how the REDD initiative is designed, managers may either receive REDD incentives based on the avoided degradation within PAs alone or based on the avoided degradation at the landscape level, the latter implying an internalization of leakage. Here we find few cases in which the optimal configurations and enforcement of PAs differs between managers who focus on the PA versus managers who focus on the landscape. Here, leakage is spread across the landscape in a no-wage case and spatial leakage is mitigated by labor allocations to wage work in the labor market setting. In the few cases of difference, typically the 
manager with the landscape perspective focuses small amounts of enforcement in more secondary PAs than does the manager focused only on avoided degradation in the PAs, while they both enforce at high levels in a primary PA. The REDD literature stresses the importance of incorporating leakage in assessing the level of avoided deforestation and forest degradation at the landscape level (Gregersen et al., 2010; Atmadja and Verchot, 2012; Albers and Robinson, 2013; Robinson et al., 2019). Our findings inform that discussion by suggesting that leakage matters less for the location decision of REDD PAs in settings with either active labor markets to absorb labor deterred from REDD PAs or in settings where spatial arbitrage opportunities have already been exploited. As in ongoing research, if, in response to REDD PAs, villagers can move their village or their resource extraction starting point to an area that faces little extraction, the level of leakage generated could be quite large because that move reduces distance costs and makes new areas available for positive rents (i.e., previously unexploited spatial arbitrage opportunities) from resource extraction.

Empirical estimates of leakage in forest settings typical examine leakage of deforestation, which is driven by different actions than the forest degradation we depict here (e.g. Robalino et al. 2017; Alix-Garcia et al., 2012). Robalino et al. (2017) motivate two potential reactions to PAs that influence leakage: the PA's restrictions increase the value of deforestation elsewhere leading to leakage and the PA's presence generating tourism benefits that reduce the value of nearby deforestation. In empirical analysis of Costa Rica's PAs, they find evidence consistent with areas in which the deforestation leakage dominates the tourism conservation incentive, and vice versa. In the context of REDD PAs, we do not expect a large tourism benefit to offset leakage of forest extraction and forest degradation. Our framework could be expanded to include a fuller representation of the forest product market to depict Robalino et al.'s mechanism of the 
PAs altering forest product supply enough to increase forest product prices, which translates to the PAs creating newly-valuable forest patches with un- or under-exploited opportunities to capture rents. The empirical work's findings of deforestation near roads are consistent with our model's predictions of higher levels of forest degradation in low distance cost patches. Although Robalino et al.'s analysis identifies heterogeneity in deforestation leakage across the landscape, the von Thunen-based approach to analyzing deforestation does not accommodate a spatial process of deforestation decisions in reaction to the PA due to its reliance on per-parcel values. In addition, the PAs in empirical analyses are not sited optimally with respect to people's reactions to the PAs and little data about enforcement actions in the PAs informs the empirical assessment of leakage in reaction to PAs.

\subsection{Burdens on people}

When conceived as a conditional payment for the ecosystem service (PES) of avoided carbon emissions, REDD payments could create avoided degradation without imposing a burden on rural forest-dependent people. Yet, enforcing the conditionality of the payment in remote forest locations could prove difficult. In addition, if rural people do not have access to markets to substitute for other products, REDD payments may not provide appropriate incentives to curb forest extraction. Perhaps most problematic, many forests are de facto open access and used by local people who have no rights to the forest, which limits the ability to form contracts for REDD payments. In some of those settings, local communities may have communal tenure and could receive payments at the village level, but that scenario raises issues of how individual incentives are created to generate avoided forest degradation.

In many such cases, communities or governments use REDD funding to enforce PAs, as explored here. Unless the payments are larger than the enforcement costs and the excess funding 
contributes to the rural people's welfare, these REDD PAs can be a burden to local people except when enforcement prevents open access extraction and a higher valued steady state occurs, as in the low budget cases here. NGOs and countries often implement policies to compensate people for the lost resource access in PAs, but unconditional payments to individuals, payments to villages, and village development projects, such as dispensaries and schools, can create higher welfare but do not create incentives for reducing forest degradation and carbon emissions from forest loss. Here, the PA's enforcement and the wage-increasing projects both create a disincentive for forest extraction and an incentive for conservation that operates through a labor allocation mechanism. In keeping with this analysis' focus on how villagers determine their labor allocation to forest extraction, we find that a wage-increasing project provides avoided forest degradation on its own, and both augments a PA's ability to generate conservation and improves villager incomes. In our framework, this result holds because villagers allocate labor across forest extraction and wage labor based on those activities' net marginal values, which implies that higher wages results in less forest extraction. In contrast to many Integrated ConservationDevelopment Projects (ICDPs) that do not include conditionality or another mechanism to integrate extractors' conservation and development decisions, the labor allocation decision links the conservation and development outcomes. The impact of a wage-increasing project on conservation outcomes would be more muted in settings with considerable surplus labor availability and in cases in which the income effect or market impacts increase the value of forest extraction. This analysis demonstrates that, in some settings, the implementation of a combined policy of PAs and projects can improve avoided forest degradation and carbon emission outcomes but the optimal combinations to generate such conservation benefits will depend on the costs of inducing higher wages and the costs of enforcing PAs, in addition to the distance setting. 
Our analysis also demonstrates that making the choices of project and PA location/enforcement simultaneously rather than sequentially improves conservation outcomes.

\section{Conclusion}

This analysis considers the use of sometimes incompletely enforced protected areas within a forest landscape to generate avoided forest degradation and carbon releases. PA siting and enforcement choices incorporate villager spatial and labor allocation decisions in reaction to the PA to determine the optimal PA policies for a given budget. The optimal PAs vary across labor market settings and across distance characteristics of the forest patches because those aspects of the setting influence villagers' decisions and reactions to PAs. Pairing wageimproving projects with (constrained) optimal PA siting and enforcement creates added avoided degradation by creating an incentive to allocate labor away from forest extraction and into wage labor. With many countries and communities forming REDD policies based on PA enforcement rather than conditional payments for avoided forest degradation, this analysis could inform the implementation of REDD PAs and increase the avoided carbon emissions produced by REDD funding and policy by reflecting the spatial decisions of extractors in response to spatial PA policy. 


\section{References}

Albers, H. J., Maloney, M., \& Robinson, E. J. Z. (2017). Economics in systematic conservation planning for lower-income countries: A literature review and assessment. International Review of Environmental and Resource Economics, 10(2), 145-182.

Albers, H. J., \& Robinson, E. J. Z. (2013). Reducing emissions from deforestation and forest degradation. Encyclopedia of Energy, Natural Resource, and Environmental Economics, $2,78-85$.

Albers, Heidi J. (2010). Spatial modeling of extraction and enforcement in developing country protected areas. Resource and Energy Economics, 32(2), 165-179.

Albers, Heidi J., \& Robinson, E. J. (2007). Spatial-temporal aspects of cost-benefit analysis for park management: An example from Khao Yai National Park, Thailand. Journal of Forest Economics, 13(2), 129-150.

Alix-Garcia, J.M., Shapiro, E.N. and Sims, K.R., 2012. Forest conservation and slippage: Evidence from Mexico’s national payments for ecosystem services program. Land Economics, 88(4), pp.613-638.

Atmadja, S. and Verchot, L., 2012. A review of the state of research, policies and strategies in addressing leakage from reducing emissions from deforestation and forest degradation (REDD+). Mitigation and Adaptation Strategies for Global Change, 17(3), pp.311-336.

Bauch, S. C., Sills, E. O., \& Pattanayak, S. K. (2014). Have we managed to integrate conservation and development? ICDP impacts in the Brazilian Amazon. World Development, 64, S135-S148.

Bayer, P., \& Timmins, C. (2005). On the equilibrium properties of locational sorting models. Journal of Urban Economics, 57(3), 462-477. https://doi.org/10.1016/j.jue.2004.12.008 
Blom, B., Sunderland, T. and Murdiyarso, D., 2010. Getting REDD to work locally: lessons learned from integrated conservation and development projects. Environmental science \& policy, 13(2), pp.164-172.

Börner, J., Wunder, S., Wertz-Kanounnikoff, S., Hyman, G., \& Nascimento, N. (2014). Forest law enforcement in the Brazilian Amazon: Costs and income effects. Global Environmental Change, 29, 294-305.

Brandon, K., \& Wells, M. (2009). Lessons for REDD+ from protected areas and integrated conservation and development projects. Realising REDD+: National Strategy and Policy Options, 225-236.

Brimont, L., Ezzine-de-Blas, D., \& Karsenty, A. (2017). The cost of making compensation payments to local forest populations in a REDD+ pilot project in Madagascar. Madagascar Conservation \& Development, 12(1).

Bruner, A. G., Gullison, R. E., \& Balmford, A. (2004). Financial costs and shortfalls of managing and expanding protected-area systems in developing countries. BioScience, 54(12), 1119-1126.

Cavendish, W. (2000). Empirical regularities in the poverty-environment relationship of rural households: Evidence from Zimbabwe. World Development, 28(11), 1979-2003.

Edmonds, E. (2002). Government initiated community resource management and local resource extraction from Nepal's forests. Journal of Development Economics 68 (1): 89-115.

Gregersen, H., El Lakany, H., Karsenty, A. and White, A., 2010. Does the opportunity cost approach indicate the real cost of REDD+? Rights and realities of paying for REDD+.

Kerr, J. and Jindal, R., 2007. Alternatives to PES for securing delivery of environmental services. USAID PES Brief 6. 
https://vtechworks.lib.vt.edu/bitstream/handle/10919/67509/3403_PESbrief6_Alternative s.pdf?sequence $=1 \&$ isAllowed $=\mathrm{y}$

Macdonald, D.H., W.L. Adamowicz, and M.K. Luckert. 2001. Fuelwood collection in northeastern Zimbabwe: valuation and caloric expenditures. Journal of Forest Economics 7(1):29-51.

Muller, J., \& Albers, H. J. (2004). Enforcement, payments, and development projects near protected areas: How the market setting determines what works where. Resource and Energy Economics, 26(2), 185-204.

Murdiyarso, D., Skutsch, M., Guariguata, M., Kanninen, M., Luttrell, C., Verweij, P., \& Martins, O. S. (2008). How do we measure and monitor forest degradation. Moving Ahead with REDD, 99-105.

Pattanayak, Subhrendu K., Erin O. Sills, and Randall A. Kramer. 2004. Seeing the forest for the fuel. Environment and Development Economics 9: 155-179.

Pearson, T. R., Brown, S., Murray, L., \& Sidman, G. (2017). Greenhouse gas emissions from tropical forest degradation: An underestimated source. Carbon Balance and Management, 12(1), 3.

Rakatama, A., Pandit, R., Ma, C. and Iftekhar, S., 2017. The costs and benefits of REDD+: A review of the literature. Forest Policy and Economics, 75, pp.103-111.

Robalino, J., Pfaff, A., \& Villalobos, L. (2017). Heterogeneous local spillovers from protected areas in Costa Rica. Journal of the Association of Environmental and Resource Economists, 4(3), 795-820. 
Robinson, E.J.Z, Albers, H.J. and Williams, J.C., 2011. Sizing reserves within a landscape: The roles of villagers' reactions and the ecological-socioeconomic setting. Land Economics, 87(2), pp.233-249.

Robinson, E.J., Somerville, S. and Albers, H.J., 2019. The Economics of REDD through an Incidence of Burdens and Benefits Lens. International Review of Environmental and Resource Economics, 13(1-2), pp.165-202.

Sato, J., \& Kawasaki, H. (2009). Discrete fixed point theorems and their application to Nash equilibrium. Taiwanese Journal of Mathematics, 13(2A), 431-440.

Sommerville, M., Jones, J. P., Rahajaharison, M., \& Milner-Gulland, E. J. (2010). The role of fairness and benefit distribution in community-based Payment for Environmental Services interventions: A case study from Menabe, Madagascar. Ecological Economics, 69(6), 1262-1271.

Sterner, E. O., Robinson, E. J., \& Albers, H. J. (2018). Location choice for renewable resource extraction with multiple non-cooperative extractors: A spatial Nash equilibrium model and numerical implementation. Letters in Spatial and Resource Sciences, 11(3), 315-331.

Sunderlin, W.D. and Sills, E.O., 2012. REDD+ projects as a hybrid of old and new forest conservation approaches. Analysing REDD+: challenges and choices. Center for International Forestry Research, Bogor, Indonesia, pp.177-191.

Timmins, C., \& Murdock, J. (2007). A revealed preference approach to the measurement of congestion in travel cost models. Journal of Environmental Economics and Management, 53(2), 230-249. https://doi.org/10.1016/j.jeem.2006.08.002 


\section{Appendix/Supplemental Information.}

I. Manager's enforcement costs as a function of distance.

The analysis in the related article explicitly models villagers' forest extraction costs as a function of distance from the village. In contrast, managers face no such spatial aspect to their enforcement costs. In practice, managers do incur costs as a function of distance for their enforcement activities. Our field observations suggest that those costs are low relative to the distance costs faced by village extractors due to differences in technology, such as the manager's patrols use of trucks and motorbikes while extractors walk or bike. In addition, the starting point for a patrol may be at any point in the landscape, including the village, some other forestproximate location, or guard stations in the forest. Due to the relative importance of the distance costs to villagers and the lack of generality about a starting point for managers' enforcement activities, we do not explore the impact of distance-based enforcement costs here. Still, a particular setting's distance-based enforcement costs can contribute to the effectiveness of enforcement (Borner et al. 2014; Albers, 2010). Here, we include a distance-based component to the enforcement costs of the managers and determine the optimal location and enforcement level of PAs for the case in which those costs occur based on distance from the village. The enforcement cost function for a patch $(r, p)$ becomes:

$$
C_{e,(r, p)}=F_{r, p}+c_{e} e_{r, p}
$$

where $F_{r, p}$ is a fixed cost of distance specific to the patch $(r, p)$ and the second term is the variable cost of enforcement $\left(c_{e}\right)$ weighted by the amount of enforcement in that patch, $e_{r, p}$. In this formulation, the manager's patrols incur the per-patch distance cost for each patch in which they enforce, unlike the extractors whose distance costs reflect their route through the forest. The manager faces the budget constraint: 


$$
B=\sum_{r, p} C_{e,(r, p)}
$$

We consider a low and a high fixed distance cost of enforcement (Table 3 ) and determine the optimal PAs and enforcement level for these cases.

Table 3: The percentage of the budget incurred as a fixed cost to a PA in a given patch for low and high fixed cost cases.

\begin{tabular}{|l|c|l|l|l|l|l|l|l|}
\hline & \multicolumn{2}{|l|}{ Patch $=1$} & \multicolumn{2}{l|}{ Patch =2 } & \multicolumn{2}{l|}{ Patch=3 } \\
\hline Case & Low & High & & Low & High & & Low & High \\
\hline $\mathrm{B}=0.5$ & $5 \%$ & $15 \%$ & & $10 \%$ & $30 \%$ & & $15 \%$ & $45 \%$ \\
\hline $\mathrm{B}=1.0$ & $2.5 \%$ & $7.5 \%$ & & $15 \%$ & $15 \%$ & & $7.5 \%$ & $22.5 \%$ \\
\hline $\mathrm{B}=1.5$ & $1.67 \%$ & $5 \%$ & & $3.33 \%$ & $10 \%$ & & $5 \%$ & $15 \%$ \\
\hline
\end{tabular}

Including distance-based enforcement costs leads to three changes in the optimal PA siting and management. First, the budget must now cover both the distance cost and in-PA enforcement, which reduces the level enforcement possible in the PAs for a given budget. For example, the total amount of enforcement declines between the no distance enforcement cost, low distance cost, and high distance cost, as evidenced by the sum of the per-patch levels of enforcement for each case at each budget (Figure 6). Second, the fixed distance cost implies that for some increases in budget, the manager optimally increases marginal enforcement in one patch rather than introducing an enforced PA in another patch because the budget increase is not large enough to cover the fixed distance cost for an additional patch. That discrete or fixed cost leads to more budgets in which fewer PAs are enforced. For example, in the high distance cost cases at the budgets of 0.5 and 1.0, the manager enforces only one PA, while the manager enforces two PAs for both the no fixed distance cost and low distance cost cases at those budgets (Figure 6). Third, the distance-based enforcement costs also induce PA locations at a lower 
distance from the village, which leaves more budget for patrol activities in those locations. For example, the optimal PAs are located in one patch near the village $(2,1)$ and one patch far from the village $(1,3)$ for the manager without distance costs and a budget of $B=1.5$ while the manager facing a low distance cost only enforces PAs nearest the village (Figure 13). These three factors interact with each other and with the villagers' extraction responses to determine the appropriate location and enforcement level of PAs in a setting with enforcers facing distance costs.
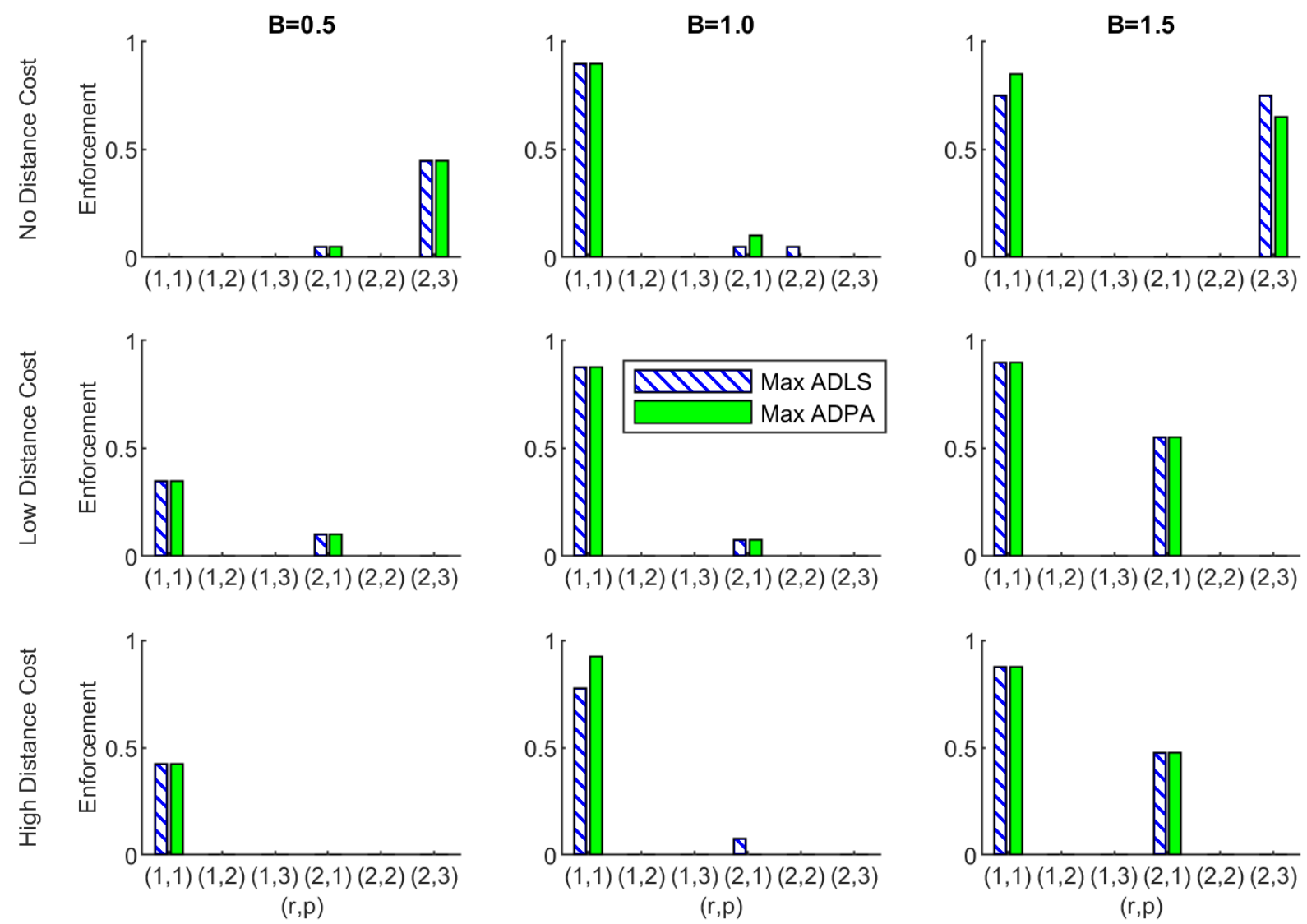

Figure 6: optimal distributions of PAs and enforcement when there is no distance cost, low distance cost, and large distance cost 


\section{Establishing PAs in all patches.}

In this article, for computational efficiency, we impose a maximum number of 3 PAs and use low enough budgets to insure that that constraint does not bind regularly. Here, we produce the outcomes with that constraint removed for the small distance setting and the large budget to demonstrate that the PA number constraint does not drive the results presented in the paper. For the unconstrained number of PAs case, the manager employs 2 PAs in the same patches and at the same optimal enforcement distribution as in the 3-PA constrained case (Figure 7, 3 PA vs. 6 PA), but determining that result more than doubles the computation time.

In addition, we examine the case in which each patch contains a PA and enforcement levels are equal across all those PAs for the high budget case. As in the article's results, because per patch harvest exhibits diminishing returns to total extraction labor, the largest decreases in harvest are accomplished by discouraging the initial units of extraction labor in a patch, which encourages the concentration of enforcement in a PA patch. The effect of concentrating enforcement can be quite large compared to spreading enforcement across the landscape (right panel of Figure 7). In contrast to this optimal concentration of enforcement in a small number of PA patches, spreading enforcement across the entire forest results in modest avoided degradation in all patches but lower landscape level avoided degradation overall. In a different setting in which ecosystem services and biodiversity protection at the landscape level result from the spatial pattern of forest degradation, other optimal patterns of PA enforcement would emerge. In the case explored here, however, carbon emissions from any patch in the forest are valued equally and linearly summed across the landscape, which focuses the placement and enforcement of optimal PAs on the spatial aspects of forest extractors' decisions. 

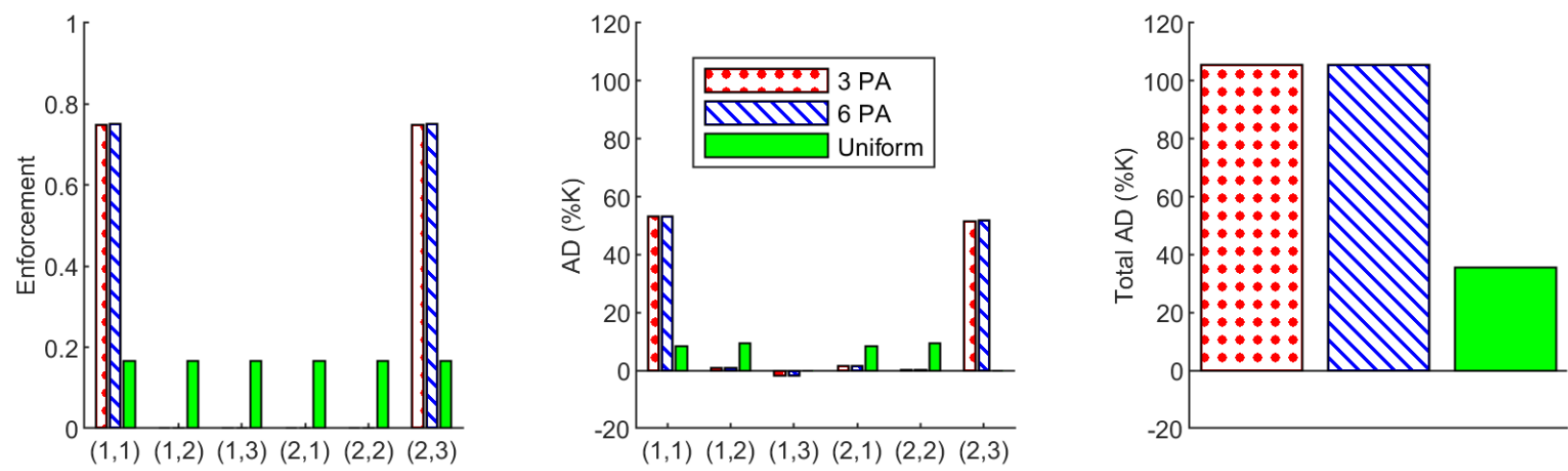

Figure 7: The optimal distribution of enforcement and PAs with a functioning labor market, low distance cost, and high budget. The results are shown with (3 PA) and without (6 PA) the 3-PA restriction during optimization, as well as the case of a uniform distribution of enforcement over 6 (non-optimal) PAs (Uniform). 